\title{
'My brain made me do it' - how neuroscience may change the insanity defence
}

According to Garland et al.:" 'If our brains are determined and if the brain is the necessary and sufficient organ that enables the mind, then we are left with the question: Are the thoughts that arise from our mind also determined? Is the free will we seem to experience just an illusion, and if the free will is an illusion, must we revise our concept of what it means to be personally responsible for our actions?'

The law can only function predictably (and reasonably fairly) by conveniently assuming that all humans exercise free will to the extent that everyone can understand the law and control their own behaviour. But the law also provides for excuses that enable some wrongdoers to escape responsibility. The general rule in South African law, as provided in Section 78 of the Criminal Procedure Act, is that mental illness (or defect) may somehow interfere with an accused's ability to appreciate that his actions were wrong, or ability to control his behaviour (even if he knew it was wrong). This provision also now includes omissions, i.e. failure to act when he or she was obliged to.

And what is this 'mental illness or defect' that so convincingly clouds reason or loosens the reins of self-control? No legislation or judicial precedent has provided a satisfactory definition, other than to indicate that 'psychiatrists know best, so ask them'. Unfortunately, the accused only has to prove on a balance of probabilities that he or she suffers from a mental illness or defect; this is considerably less stringent than the 'beyond reasonable doubt' test that is used in proving guilt in criminal proceedings. And legislation now allows that 'if it is alleged at criminal proceedings that the accused is by reason of mental illness or mental defect or for any other reason [my italics] not criminally responsible for the offence charged ... direct that the matter be enquired into and be reported'. The limits of 'any other reason' are not addressed, but conceivably could refer to anything about an accused that puzzles the court. It now seems that the ambit of excuses has been so broadened that, theoretically, any lawyer, with the aid of the requisite expert, can convince a court that an otherwise normal person's momentary catastrophic behaviour was the result of a pathological process.

The psychoanalysts started the rot. They provided convoluted (but untested) formulations in which ids, egos and superegos engaged in eternal struggles, and where emotionally distant fathers and domineering mothers were the causes of terrible oedipal land other) conflicts that influenced their thoughts, feelings and, ultimately, behaviour. They presented the courts with a consistent heady brew of determinism in which the overriding message was that we all have been influenced by antecedent events, out of our control, which apparently rob us of freedom of choice.

Courts have gradually become bemused by these un-testable parables; how, for example, does one verify that a particular dynamic actually did operate those many years previously and, even if it did, by what stretch of deduction can it ever be proved that any childhood phenomenon is causally linked to a particular crime committed in adulthood? Nevertheless, ardent analysts still continue to peddle their potted theories derived from one of the many long-dead fantasists (otherwise revered as theorists), and sometimes our courts still swallow these pseudoscientific pronouncements. The recent history of our non-pathological incapacity defence, in which strange terms such as 'emotional storm', 'catathymic crisis' and 'disintegrated ego' (inter alia) have been used to explain why an accused was not responsible for killing an intimate, remains as a testament to these unscientific musings. In every case, the real explanation was that the accused was just very very angry. The Court of Appeal eventually ruled in S v. Eadie (2) 2001 (1) SACR 185 that, for this defence to succeed, there has to be objective evidence (primarily by the nature of the accused's actions) that he had acted in a state of automatism

Undoubtedly, an added difficulty in our legal system is that the courts have not really ruled on the admissibility of psychiatric or psychological evidence. In the USA, the parameters of expert testimony were set out in the landmark Daubert v. Merrell Dow Pharmaceuticals Inc case, by which psychiatric opinions offered during expert testimony essentially have to be held with 'reasonable medical certainty'. ${ }^{2}$ South African courts must surely also follow this example, which will force experts to provide the courts with evidence that the opinions which they offer are supported in the scientific literature, and have been obtained using acceptable methodology. Unfortunately, the researchers who produce the enormous amounts of information in our journals almost never consider that these may have psycho-legal implications. This editorial merely attempts to demonstrate how a minute snapshot of some current findings in the neuroscience literature could conceivably have interesting effects on the current conceptualisation and practice of the insanity defence.

\section{We cannot think before we leap}

Over the past 20 years - despite the plethora of research on the functioning of the brain - we do not (to date) understand fully how 
the brain produces subjective experience, processes information and controls behaviour. But some findings suggest that our assumptions about free will and agency may not be true.

An intriguing starting point is Libet's findings in the 1980s that the brain initiates volitional activity in response to a somatosensory stimulus at least $350 \mathrm{~ms}$ before the individual is aware of wanting to act, and that 'subjective antedating' occurs by which this is experienced as having occurred without delay. ${ }^{3}$ Libet did postulate that, somehow, conscious processes could still modify or veto the process, which of course created a paradox: if decisions to act occur unconsciously, then how is it possible to recruit a conscious process to influence it? In a sophisticated refinement, a recent study asked subjects to fixate on a screen, where a stream of letters was presented. Simultaneously they were being monitored by functional MRI (fMRI) scanning. At some time they were instructed that, when they felt the urge to do so, they were freely to decide between pressing one of two buttons, under their right and left index fingers, and press the button immediately. In parallel, they had to remember the letter that was on the screen when their decision was consciously made. Generally, the frontopolar cortex displayed fMRI signals about 7 seconds before the subjects registered their decisions to move. The investigators were able to predict which finger a subject was about to use before the subjects themselves were aware, even though it was the subjects' own decision which finger they would use. ${ }^{4}$ Somehow, it seems, even our so-called voluntary acts are initiated and controlled without conscious awareness.

Ironically, it has long been recognised that most human activity occurs in a 'semi-automatic' state. Just about everything we do, especially when it involves previously well-rehearsed routines, proceeds apparently with minimal ongoing conscious control. These include complex tasks such as driving a car, dressing, typing, etc., which are typically followed by some degree of amnesia. This phenomenon has long been regarded as a manifestation of dissociation in everyday life, which confusingly is not easily differentiated from the fragmentary experiences of the other aspects of dissociation (such as depersonalisation and derealisation) that apparently operate to minimise the overwhelming effects of past trauma. ${ }^{5}$ But for the legal concept of mens rea to have meaning, the perpetrator of an offence must be able to have the experience of 'mineness' for his actions; this requires having both a sense of agency ('I am the originator of my actions') and a sense of ownership ('The body parts that did or did not move are actually mine'). There is now a growing consensus that the acceptance of both these agencies really depends on the illusion that a vast diversity of basic representations (that are not necessarily experienced consciously, such as position sense) are united with a hierarchy of higher-order representations, so producing a seemingly seamless state of awareness and consciousness. ${ }^{6}$ Therefore, not only is this sensation that we have of being rational and in control an illusion but it is also fragile and easily disrupted.

But if our actions are determined by cognitive processes that are truly unconscious (i.e. beyond momentary awareness), can we be regarded as blameworthy and responsible for our wrongdoings? Consider the recent and growing research into 'mirror neurons'. These are probably part of a neural network that involves most cortical areas (especially in the inferior parietal lobule, precentral gyrus and posterior part of the inferior frontal gyrus) that seems important for the cortical representation of sequential information and for learning from the observation of patterns of behaviour of others. This is believed to be the neural basis of empathy and, by extrapolation, moral behaviour, in that it enables one to put oneself in another's place. Input from the limbic system, such as anger or fear from the amygdala, may be the underlying mechanism by which this appreciation of what is morally acceptable gains emotional valence. Hence our horror when we contemplate the murder of others, or our anger when learning that others have been wronged. Witnessing such actions in others causes a vicarious experience in ourselves and, of course, individuals vary to the degree by which they are capable of this. Presumably it will be possible in the future to visualise defects in these neural systems with some advanced neuroradiological or neurophysiological technique.

\section{The paradox of objective findings}

The diagnoses of serious psychiatric disorders (which satisfy the legal definition of 'mental illness') do not generally depend on objective findings, such as brain scans (except for a few disorders such as the dementias). Therefore, the courts currently almost exclusively have to accept the expert's clinical judgement, or decide between competing clinical judgements. But, if neuroscience continues to provide objective and observable evidence that we humans do not consciously make decisions or control our behaviour, it may be feasible to determine whether some people have deficits in these mechanisms, which in turn may lead to the curious situation that it may become easier to excuse defendants who are not mentally ill but have clearly demonstrable problems in their brain circuitry, than those who are obviously insane but whose pathology cannot be confirmed objectively.

Even though the Daubert standard is not part of South African law, it is foreseeable that our courts will readily accept neuroimaging and neurophysiological evidence, which could result in some interesting precedents. A cursory glance through our juridical history will immediately reveal how often our courts have made some rather curious decisions based on somewhat idiosyncratic testimony from an accepted expert. We now have 
the imminent possibility that neurophysiological findings will be brandished in court to support the notion that an accused's ability to act consciously was absent and that his brain (and not he) was responsible for his reprehensible behaviour. And the accused will probably display no other signs or symptoms suggesting that he suffers from any known mental disorder.

Many authorities dispute that the courts will succumb to these arguments, based on their understanding that the law assumes that every person possesses free will and acts rationally, and that this entails discussions about philosophical values that the concrete world of neuroscience cannot deal with. In these authorities' view, neuroscience cannot comment on whether humans are responsible for their behaviour because it is unable to provide definitive tests for legal responsibility. ${ }^{8}$ In other words, they contend, one cannot produce a brain scan as proof that a defendant lacks legal or criminal responsibility. These writers probably have had minimal experience in testifying in court, and are arguing from mostly a theoretical (and perhaps naive) perspective. The truth is that we routinely use medical findings to support our clinical assessments. Another truth is that automatism is a bedrock defence in our law las the sine qua non of the non-pathological incapacity defence), and the above neurophysiological findings would surely reinforce the assertion that a particular accused acted in a state of automatism because his requisite brain circuits display significantly longer delays before reaching conscious awareness than those of 'normal' others, and therefore he could not consciously control his behaviour. The courts generally appreciate this sort of concrete evidence, and it is conceivable that, in the relatively near future, those defendants will be acquitted for murder for whom enough doubt was generated concerning their ability to control themselves. Then, the insanity defence will truly be insane.

\section{Sean Z Kaliski}

Department of Psychiatry

University of Cape Town, and

Forensic Mental Health Service

Valkenberg and Lentegeur hospitals

Cape Town

1. Garland B, Frankel MS. Neuroscience and the Law. Washington, DC: Dana Press, 2004: 9

2. Poythress NG. "Reasonable Medical Certainty": Can we meet Daubert standards in Insanity cases? J Am Acad Psychiatry Law 2004; 32: 228-230.

3. Libet B. The timing of mental events: Libet's experimental findings and their implications. Conscious Cogn 2002; 1 1: 291-299

4. Soon CS, Brass M, Heinze H, Haybes JD. Unconsious determinants of free decisions in the human brain. Nat Neurosci 2008; 1 1 (5): 543-545.

5. Steinberg M. Handbook for the Assessment of Dissociation. A Clinical Guide. Washington: American Psychiatric Press, 1995.

6. Synofzik M, Vosgerau G, Newen A. I move, therefore I am: A new theoretical framework to investigate agency and ownership. Conscious Cogn 2008; 17:411424

7. Tancredi L. Hardwired Behavior. What Neuroscience Reveals about Morality. New York: Cambridge University Press, 2005.

8. Waldbaver JR, Gazzaniga M. The divergence of neuroscience and law. Jurimetrics $2001 ; 41: 357-364$ 